\title{
Building new business model from multiple case study research in the Internet of Me
}

\author{
Roberto RUGGIERI \\ University "La Sapienza” of Rome, Rome, Italy \\ roberto.ruggieri@uniroma1.it \\ Francesca ROSSETTI \\ University "La Sapienza” of Rome, Rome, Italy \\ Fabrizio D'ASCENZO \\ University "La Sapienza” of Rome, Rome, Italy \\ Lucio CAPPELLI \\ University of Cassino and Southern Lazio, Cassino, Italy \\ University "La Sapienza" of Rome, Rome, Italy
}

\begin{abstract}
The digital revolution has greatly changed the approach to culture, work, leisure time, the way we interact and communicate with people: the digitization of information has taken root and has become essential in all areas of social life as a phenomenon that guides and monitors the transformation of society in all its various forms, bringing great changes in almost all areas and especially in the world of work and industry. One of the core elements of the fourth industrial revolution is the systematic application of IoT technologies (Internet of Things) and IoM (Internet of Me) to production processes on a global scale. This study seeks to identify the main decision in the IoT/IoM pattern innovation, more specifically, the purpose of the paper is primarily an analysis of what are the possible future benefits of IoT and IoM, trying to understand the effort and their opportunities for a consumer oriented business. Then to analyze the competitive advantage that companies are pursuing when they implement a business which is IoT/IoM oriented. Our research aims to address the following two research questions: 1)Does exist a well-structured business model for the companies IoT/IoM service oriented? and 2)Is it possible to standardize behavioral pattern and to draw guidelines for companies who want to start similar strategic management? The research presents two phases methodologically joined between them: from a theoretical point of view it is defined the change from the business model towards the "ecosystem" of business model in the strategy IoT/IoM oriented, and from a empirical point of view the business development of an Italian start-up first mover group in the sectors involved in IoT and IoM revolution, through the direct interview qualitative tool.
\end{abstract}

Keywords: Industry 4.0, Internet of Things, Internet of me, Business Model, Cyber-physical Sistem.

\section{Introduction}

The Internet of Things (IoT) is an ecosystem made up of standard technologies and sensors that allow factory objects, devices and finished products, to communicate and interact with each other via network (Machine to Machine - M2M) and people (Human to Machine $\mathrm{H} 2 \mathrm{M}$ ). Through the introduction of this paradigm, the analysis and decision-making is decentralized, enabling real-time response. The IoT is a term coined by Kevin Ashton in 1998. All the surrounding things connected to the network, providing access to information 
(Gomez et al., 2013). Then it describes the interconnection of the objects, allowing the identification, the communication and the data collection (Oriwoh et al., 2013). The IoT should change the business, the information, and the related social processes, providing unexpected possibilities (Cluster of European Projects on the Internet of Things, 2009). Kyriazis and Varvarigou (2013) suggested that the IoT digital environment enables the provision of added-value applications, exploiting a crowd of devices contributing to the information. Furthermore, the authors highlight the approaches that allow things to become smarter, autonomous and reliable.

In this context, the research on IoT and related business models from the ecosystem perspective does not exist: the studies have focused on a single firm's business model (Uckelmann et al., 2011; Leminen et al., 2012).

The aim of this paper is to analyze what are the possible future benefits of IoT and IoM, trying to understand the effort and their opportunities for a consumer oriented business. Furthermore, the intention is to investigate the competitive advantage that companies are pursuing when they implement a business which is IoT/IoM oriented. This study seeks to identify the main decision in the IoT/IoM pattern innovation, more specifically, our research aims to address the following two research questions (RQ): oriented?

RQ1: Does exist a well-structured business model for the companies IoT/IoM service

RQ2: Is it possible to standardize behavioral pattern and to drawn guidelines for companies who want to start similar strategic management?

The research presents two phases methodologically joined between them: from a theoretical point of view it is defined the change from the business model towards the "ecosystem" of business model in the strategy IoT/IoM oriented, and from a empirical point of view the business development of an Italian start-up first mover group in the sectors involved in IoT and IoM revolution, through the direct interview qualitative tool.

\section{Theoretical background}

In light of the research questions addressed in this study, the following subchapter briefly outlines the key concept related to the switch from the business model towards the "ecosystem" business model in the perspective Internet of Things/Internet of Me. Thus, this section provides the theoretical foundation and defines the scope of the research.

\section{From the Business Model towards the "ecosystem" Business Model}

Business Models are considered as a point of contact between technology, organization and strategy, with the aim of describing how an organization draws its value from a technology and exploits it as a competitive advantage source over time (Osterwalder et al., 2005). In an attempt to solve the problems that arise from the fragmentation of this area of research, numerous interventions leading to the definition of frameworks, classifications and taxonomies have been developed (Bienstock et al., 2002; Gordijn and Tan, 2005; Osterwalder et al., 2005; Pateli and Giaglis, 2003; Shafer et al., 2005). Despite these efforts, there is still no unanimous approval.

Recently, the attention around business models has changed: businesses are becoming part of complex ecosystem. This intricacy increases when shifting from centralized structures towards decentralized and distributed network structures (Barabasi, 
2002; Möller et al., 2005). The structures highlight different kind of activities in the ecosystem, and a continuous growing level of complexity require new value systems (Möller et al., 2005).

According to Muegge (2011) the business ecosystems are an institution of participation "where organizations and individuals typically self-identify as an ecosystem, both in their own internal discourse and in the brand identity they convey to others". Moreover, the business ecosystem is "an economic community supported by a foundation of interacting organizations and individuals - the organisms of the business world." (Moore, 1996). A business ecosystem taking into account customers, lead producers, competitors, stakeholders and shareholder. The author discusses that the key to a business ecosystem are leadership companies and these have an influence which refers to the co-evolutionary processes.

According to Peltoniemi (2005) "the system is more than the sum of its parts" and the operating system could be realized by studying its parts connected to the entity. Therefore, the author claims the socioeconomic system such as an adaptive complex system, where population creates a self-organization of emergence, adapting to the environment. The literature on business ecosystems requires a much deeper view of interrelated system of the business models (Carbone, 2009; Muegge, 2013).

A business ecosystem is an organization of economic actors whose individual business activities are related to the platform, namely things organization. The platform characterizes the core of a business ecosystem (Cusumano and Gawer, 2002). Muegge (2011) describes a platform as a "set of technological building blocks and complementary assets that companies and individuals can use and consume to develop complementary products, technologies, and services". In the technological platform, we can consider the connection -via internet- of objects from the physical world that are equipped with sensors, actuators and communication technology. The IoT ecosystem is therefore the interconnection of the virtual world of the Internet with the physical world of things (Westerlund et al., 2014; Mazhelis et al., 2012).

A necessary, but not sufficient, condition for the development of the IoT field is the correlation of the technical and business elements that requires a well-structured business model in order to establish what the companies offer to the customer, who are they and how they operate to deliver the product/service so that they can create a profitable and sustainable business. Three steps depicted have a great impact on the choice of modelling approach to be taken.

Traditional business models seem not to exceed the limits about the identification and analysis the value proposition in the intended IoT based service.

Nowadays, the business models fail to analyse the interdependent nature of success of the enterprises that are evolving in the same innovation ecosystem (Weiller and Neely, 2013).

Therefore, according to Fleish, Weinberger and Wortmann (2014), we can consider their study which includes the analysis 55 business model patterns from Gasmann and any Internet of Things applications regarding to their value-creating steps. This research help us to embody the opportunities and the limitations of the Internet of Things technical capacities. However, the results not would seem lead to a well-structured and defined business model patterns for the companies IoT/IoM service oriented. The biggest challenge of the Internet of Things is not only to identify 1) the needs and find everything for the 
companies, 2) the alignment of skills within the team, and 3) the maturity of the market for the novel IoT technology. It could extend this vision as well as identify and analyse three contemporary challenges of designing ecosystem business models for the IoT (Westerlund et al., 2014): the diversity of objects, the immaturity of innovation, and the unstructured ecosystems.

The problem associated with the objects diversity regards to the difficulty of designing business models for the youth because there is a multitude of different connected devices without the accepted standards. According to this, it will be extremely difficult to have standardized interfaces with which may be connected to the Internet. The diversity of objects also involves another important challenge for managers: simultaneously connect an object, a thing, a business and a consumer (Leminen et al., 2012). Thus, a continuum of possible business models is growing (Westerlund et al., 2014).

Espada et al., (2011) reminder that physical objects, named "things", are available in digital format. The digital elements of virtual objects have a specific purpose, namely to understand and include a set of data, by performing specific actions, supplementing other physical objects, requiring business logics.

Innovation refers to the immaturity of emerging technologies disorder and their components. The IoT innovations have not yet been processed into products and/or services.

This involves a non-standardization and a non-modularization of the use. The developers with coupling components can experience the creation of new products-services for youth ecosystem, learn from the experiences of the market for design and implement business models. The model of the technology adoption lifecycle (Moore, 2006) recognizes five types of adopters of innovation: innovators, early adopters, early majority, late majority and laggards. Downes and Nunes (2013) state that new digital platforms, underlying the IoT, does not follow the five-step model of Moore: new products will improve with the support of test users, rapidly embracing the majority of the market. The innovation will be mature enough for customers.

The unstructured ecosystem structures, governance, roles and underlying logic are not properly defined. Practice new business opportunities means opening new relationships or extend existing ones, it takes time and a real challenge for managers of the industries involved. The aspect of the entire ecosystem complex is associated with the number of participants (Möller et al., 2005), and an early ecosystem is like a chaotic playground.

The IoT is in its primitive stage. Today, it is too difficult to tell which will be the significant yet evolving ecosystems in the IoT field and which participant(s) will become keystone players within them (Westerlund et al., 2014). Such stakeholder could be an object/device supplier, a supplier of software infrastructure, an IoT operator, a data analyzer or a value-added service provider (Carbone, 2009). It would be better to focus on the capture of value in the ecosystems.

Therefore, identify IoT-specific business model in order to investigate on the ecosystems and band articulate this integrated value for the stakeholders is fundamental to resolve the unstructured IoT ecosystems issue. 


\section{Research design}

This study is a first attempt to analyze IoT-based business model innovation, focusing on the relevant decision criteria. To reach this goal, the research team chose a qualitative multiple-case study approach, based on semi-structured interviews. A qualitative research approach is especially appropriate to answer the research questions of this paper. A qualitative approach seems right to analyze realistic IoT oriented business model innovations and their development process.

From the interviews a text analysis has been conducted in order to search the keywords that allowed the identification of the drivers that have defined the choice of IoT and IoM technology. The software used, BanxiaDecision Explorer, has identified some verbal clusters and the co-occurrences. Next, a study on the Centrality Analysis has been carried out and the results showed some affinity among the business models used by companies.

The objective of the research is to demonstrate that the IoM and IoT technologies can be decisive in a business model development. For this purpose, a group of Italian companies, mostly startups, were contacted. The method used for this work has mainly been a qualitative method, in form of interviews with considered companies. The interview has been structured to cover five areas of interest for this study: personal data, basic information about the technology products, customer feedback and reasons that led to the products IoT/IoM development, competitors and partnership, strategic intent.

\section{Multiple case study analysis}

The study sample has been represented by four companies.

Brain Srl: activity tracker, namely an IoT device, dedicated to the two-wheel world, and in general to all extreme sports.

Motorialab: technological solutions, high-resolution services and data for outdoor sports, based on wellness and safety. The technology used will be able to fuse environmental data flows together with classified signals coming from products sensors and return feedback based on user location. These sensors allow to monitor their performance, record personal data and create their individual profiles. The mission is to provide location based feedback to users and outdoor corporate.

BEPS Engineering: Products and services in IT environment and, in particular, inside the Embedded System ecosystem. During these years, BEPS has improved its offer in some fields very close to Embedded, IoT and IoX: CLOUD solutions, personal portable systems, Sensor, Wearable.

BeFit: focused on making living and eating well a smart activity. The company's mission is to optimize and make interactive the nutritional activities of people, providing assistance in holding a calculation of the calories and eaten foods.

The Text Analysis has shown different important investment areas and these were therefore analyzed to understand the investments choice; such areas can be divided as follows: Application, Innovative Drivers, Partnership and Competitors, Prototype Hardware, Internet of Me and Tailored Customization, Data Privacy Policy, User Experience. 


\section{Application}

An important key word coming from text analysis is application. The programming context of the software plays a key role within the choices of investment and innovation. The success of a business in IoT or IoM field mainly comes from the appeal that the application may have on the customer and its features. First, of main importance is the easiness of the application (or of the software) in order to determine an, at least, acceptable usability grade.

There are some opinions that assert that three "taps" or clicks of the mouse must not be exceeded, especially when there are essential functions related.

Moreover, the application has always to be connected to IoT devices. In an IoM business oriented market, the app must be provided by a dedicated interface in order to allow the full exploitation of main features and to make a diagnosis of occurring hardware problems of the device. Design too has to be cited and it has to be studied in order to attract and stimulate the user to try new functions.

Where it has been forecasted, it needs to point out particular events and must have the possibility to interface with social networks in order to share third part applications that may improve the final experience. As an example, we can mention the Starbucks app that represents easiness and functionality and, therefore is very appreciated and downloaded.

Other apps instead, even if providing an impressive number of functions, are difficult to manage and certainly are not frequently used in everyday life.

\section{Innovative Drivers}

Innovative drivers have been different according to the examined business case. Text analysis in this case has not been so productive in pointing out those key variables that have determined the beginning of the innovative process, considered the different contexts. This diversity may be intended as a puzzle where some features of a case study have been mixed with another case, determining a fuzzy framework.

- Brain

In the Brain company of Padua, what was missing in the market has been the main determinant of the decision to enter the market and of the start up constitution. A device capable to read track data was the missing part of a business dominated by cams allowing the registration of video and images. Furthermore, the strong influence that accidents have on the driver has created the base for the definition of an offer made by a device that allows, in case of an accident, to immediately call the rescue and a series of preferred numbers in order to increase the effectiveness of first aid and raise the possibilities of immediate hospitalization for accident victims.

\section{- MotoriaLab}

The company coming from Trentino Alto Adige region, born as a spin off of Kessler Foundation, is well known in Trento area for its research activity in the field of climate conditions sensors and environmental impact on the economy of the region. Their experience in that sector, combined with the will to optimize all rescue activities in outdoor sports, conducted to the spin off MotoriaLab. 
- Beps Engineering

Concerning Beps, the need to answer for the first time to customer requests has created a situation of demand pull. The situation that makes it unique is determined from the fact that this request has started the creation of a business unit of the company of Turin dedicated to all the world IoT an VR.

- BeFit

In this case, the innovation driver has been the need to monitor assumed calories during the whole day, combined with the fact that there was no business specifically created for this need in the world of smart wellness, with large popularity nowadays thanks to the activity trackers.

\section{Partnership and Competitors}

This interesting point is related to the operability and the connectivity between the business IoM and IoT. More and more often competitor companies create a joint venture or start collaborations in several different sectors. Improvement and success, especially in the field IOM, is the result of skills mix enhanced and developed by participants in the various projects. This added value can determine the success of the applications related to the world of the Internet of Me.

\section{Prototype Hardware}

The dependence on hardware is a factor that does not appear, in the selected sample of companies, like a factor of success for business. It is not essential to have a proprietary device, but it is necessary for the application to maintain good security protocols and a good management of connections with the connected devices.

The search for new standards to support new demands, defines new protocols to supplement or replace the previous. This means that the developers also have to rethink the compatibility with new devices or smartphones embodying the latest technologies. The key issue is the reduction of sensor costs, dependent on production conducted in places where costs are lower. The common factor of the analyzed companies is the use of low cost hardware components, which, at the same, time determine a high modularity.

\section{Internet of Me and Tailored Customization}

A fundamental element which characterizes the evolution of the connected devices is the tailored customization. The analysis has highlighted that this involves the achievement of high rates of customer satisfaction, and that, if adequately exploited, can become a lever for Customer Delight. It is necessary to underline that this concept is also associated to the exploitation of the individual user data and its profiling, which is, in turn, related to the consent to the monitoring of its activities given by the customer.

Nowadays, profiling is done on a large scale, requiring a less compelling privacy respect if compared to a more strict and personal user monitoring. Companies investigated in the study sample have shown to be more coherent among them in indicating to be necessary that customer understands potentialities and opportunities coming from Internet of Me. This goal is not easy to achieve at the present moment, especially in the Italian market, because the average consumer is particularly skeptical about it. The needs of the context and the still unclear legislation only favor a partial exploitation of user data. 
At the present moment, the discrepancy lies in the fact that companies can not push on data exclusivity customization, still being forced to analyze only a simple segmented data aggregation. As already said, a boost may specifically come from those market sectors that have the purpose to improve aspects such as safety and health, in which it is possible to observe a higher propensity for users to be monitored; it may be, therefore, supposed, that these (biomedical first) will be the leading sectors for Internet of Me.

PICBE | 859

If we assume that these markets will be more flexible than others, it is possible to consider the hypothesis of a corporate business in which the personalization becomes tailored, or, better, tailored for the user. This one, accepting data processing in order to facilitate the search for those specifically personalized services, will obtain extra benefits in terms of prevention, reduction of costs and waiting times as well as, of course, in the field of wellness and health.

The exploitation of specifically personalized services for the single user will allow companies to increase returns and loyalty with that customer segment that will authorize (only after informed consent) the processing of data for discovering actions, or aimed towards finding connections and relationships among specific personal data and adverse events or business opportunities. What emerges from the study of the considered multiple cases is that small but well-designed services can become real "Killer Application" on the market, showing to be successful and well accepted by the average consumer.

All this should be seen from a non-invasive point of view, aiming to improve an existing product or service. For this reason, it is fundamental the approval given by pioneer user, who first experiments the improvements, even in a beta phase. It has to be underlined that a tailored customization, nowadays, is very difficult.; the pool of companies, at least for the moment, aims to a study made on more or less uniform segments, coming from the fact having a database for each single customer would determine unaffordable costs for a startup rather than a globally affirmed multinational.

\section{Data Privacy Policy}

Privacy protection is a main obstacle for companies that want to enter this market environment. Generally the trend that leaks out from the analysis is to treat the data as an aggregate, without entering into the specific strings of sensitive data that are more easily associated to a person. This makes difficult switching from the business 'Internet of Things'

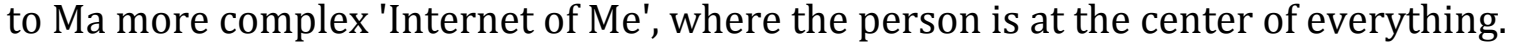

In fact, the aggregation of data generates only customer segments, while what is really to be investigated is a single relationship with the person, and this relationship may be reached only if the person feels safe to give the control over his behavior and his habits to that particular company. The quantum leap will occur when the company will 'force' the user to think about the benefits that a monitoring of its activities may have on his lifestyle.

That's why many companies prefer a business oriented to the security or well-being, which are aspects where the user is more sensitive and where he can reach a sort of compromise. But all this must be guaranteed by the state, which has to make efforts in promulgating specific laws on this topic.

\section{User Experience}

The UX is the fundamental point of IoT business and especially IoM business. The user experience should be determined at the design stage by highlighting the characteristics and 
the needs of users, focusing on the context of use (in some cases a long beta period is planned). Just for this, a wise use of IoT and IoM tools can provide a good base of data on what the customer wants, as long as the same consent to the processing of his data. From this point of view, it will be crucial to see how the user will react and what the developments will be in terms of privacy. In any case, in order to manage and understand customer needs, a deep and intense staff training work should also be made, which is a key to understanding the value of the average user needs.

\section{Conclusion}

The study provides starting points for reflection and discussion about the building new business model in the Internet of Me. From the results of empirical part we can establish that do not exist a well-structured business model for the companies IoT/IoM service oriented, however it is possible to standardize behavioral pattern and to drawn guidelines for companies who want to start similar strategic management.

Furthermore, most favoured companies will be those that belong to the countries that have fewer limitations on data processing, showing to be more reactive in applications developing and in personal monitoring. The business areas, which will drive this spread of connected objects, will be health and safety.

In the cost analysis, the reduced hardware investments will facilitate the structuring and the development of a useful and functional software for the user. The company can provide customized services, continuously improving the products. In addition, it is essential to have a software interfaced with all of the most common connection standards and that may run on most hardware devices connected with other IoT. It is the way which the company communicates with its users, and it must reflect their expectations.

Finally, it is the consumer who has to give his consent for the processing of the data. At this stage, an important part of the strategy for the success is the economic return characterized by investment in security and the image of the company. The added value that it transmits to customers has to be perceived as a quality warranty for a customer to rely on that company. It is a long and difficult job but the results that may come from this policy will certainly be turned in high revenues for the companies.

\section{References}

Barabasi, A. L. (2002). Linked: The New Science of Network. Cambridge: Perseus Publishing. Bienstock, C., Gillenson, M., Sanders, T. (2002). A Typology of E-Commerce Business Models. Quarterly Journal of Electronic Commerce, 3, 173-182.

Carbone, P. (2009). The Emerging Promise of Business Ecosystems. Open Source Business Resource, 1, 11-16.

CERP-IoT. (2009). Internet of Things Strategic Research Roadmap. Cluster of European Projects.

Cusumano M.A., Gawer, A. (2002). The Elements of Platform Leadership. MIT Sloan Management Review, 43, 51-58.

Downes, L., Nunes, P.F. (2013). Big-Bang Disruption. Harvard Business Review, 91, 44-56. 
Espada, J.P., Martinez, O.S., Garcia-Bustelo, B.C.P., Lovelle, J.M.C. (2011). Virtual Objects on the Internet of Things. International Journal of Artificial Intelligence and Interactive Multimedia, 1, 24-30.

Fleish, E., Weinberger, M., Wortmann, F. (2014). Business Model and the Internet of Thigs. Report Bosch IoT Lab White Paper.

Gomez, J., Huete, J.F., Hoyos, O., Perez, L., Grigori, D. (2013). Interaction System Based on Internet of Things as Support for Education. Procedia Computer Science, 21, 132139.

Gordijn J., Tan Y. H. (2005). A design methodology for modeling trustworthy value webs. International Journal of Electronic Commerce, 9, 31 - 48.

Kyriazis, D., Varvarigou, T. (2013). Smart, Autonomous and Reliable Internet of Things. Procedia Computer Science, 21, 442-448.

Leminen, S., Westerlund, M., Rajahonka, M., Siuruainen, R. (2012). Towards IOT Ecosystems and Business Models. In Andreev, S., Balandin, S., Koucheryavy, Y. (Eds.). Internet of Things, Smart Spaces, and Next Generation Networking, Springer, Lecture Notes in Computer Science, 7469, 15-26.

Mazhelis, O., Luoma, E., \& Warma, H. (2012). Defining an Internet-of- Things Ecosystem. In Andreev, S., Balandin, S., Koucheryavy, Y. (Eds.). Internet of Things, Smart Spaces, and Next Generation Networking, Springer, Lecture Notes in Computer Science, 7469, 1-14.

Möller, K., Rajala, A., and Svahn, S. (2005). Strategic business nets-their type and management. Journal of Business Research, 58, 1274-1284.

Moore, G.R. (2006). Crossing the Chasm-Marketing and Selling Technology Products to Mainstream Customers. (2nd Ed). Padstow: Cornwall: Capstone Publishing Ltd.

Moore, J.F. (1996). The Death of Competition: Leadership \& Strategy in the Age of Business Ecosystems. New York: Harper Business.

Muegge, S. (2011). Business Ecosystems as Institutions of Participation: A Systems Perspective on Community-Developed Platforms, Technology Innovation Management Review, 1, 4-13.

Muegge, S. (2013). Platforms, Communities, and Business Ecosystems: Lessons Learned About Technology Entrepreneurship in an Interconnected World. Technology Innovation Management Review, 3, 5-15.

Oriwoh, E., Sant, P., Epiphaniou, G. (2013). Guidelines for Internet of Things Deployment Approaches - The Thing Commandments. Procedia Computer Science, 21, 122-131.

Osterwalder, Alexander; Pigneur, Yves; and Tucci, Christopher L. (2005). Clarifying Business Models: Origins, Present, and Future of the Concept. Communications of the Association for Information Systems, 16, 1-25.

Pateli A. G., Giaglis M. (2003). A framework for understanding and analysing eBusiness Models. 16th Bled eCommerce Conference eTransformation, Bled, Slovenia, June 911.

Peltoniemi, M. (2005). Business Ecosystem: A Conceptual Model of an Organization Population from the Perspectives of Complexity and Evolution. Research Reports 18. Tampere, Finland: E-Business Research Center.

Shafer S. M., Smith H. J., Linder J. C. (2005). The power of Business Models. Business Horizons, 48, $199-207$. 
Uckelmann, D., Harrison, M., Michahelles, F. (2011). An Architectural Approach Towards the Future Internet of Things. In Uckelmann, D., Harrison, M., Michahelles, F., (Eds.), Springer, Architecting the Internet of Things, 1-24.

Weiller, C., Neely, A. (2013). Business Model Design in an Ecosystem Context. University of Cambridge Working Papers. Cambridge, UK: Cambridge Service Alliance.

Westerlund, M., Leminen, S., Rajahonka, M. (2014). Designing Business Models for the Internet of Things, Technology Innovation Management Review, 1, 5-14.

Wurster, L.F. (2014). Emerging Technology Analysis: Software Licensing and Entitlement Management Is the Key to Monetizing the Internet of Things. Gartner Research Report. Stamford, USA: Gartner, Inc. 